\title{
Participación defectuosa en la era digital
}

\section{Sobre los efectos de la desinformación en el sujeto}

\section{Defective participation in the}

digital era

\section{On the effects of disinformation and misinformation}

\section{on the subject}

\section{Participação defeituosa na era digital Sobre os efeitos da desinformação no sujeito}

\section{TAMARA JESÚS CHIBEY RIVAS}

tchibey@gmail.com - Universidad Alberto Hurtado, Chile.

ORCID: https://orcid.org/0000-0003-3670-4598

CÓMO CITAR: Chibey Rivas, T. J. (2021). Participación defectuosa en la era digital. Sobrelos efectos dela desinformación en el sujeto. InMediaciones de laComunicación, 16(2),83-102.DOI:https://www. doi.org/10.18861/ic.2021.16.2.3157

Fecha de recepción: 26 de febrero de 2021

Fecha de aceptación: 30 de mayo de 2021

\section{RESUMEN}

Desde fines del siglo XX, la sociedad ha experimentado una transformación digital. La vida social se ha transformadoyopera en un espacio digitalizado donde la información ya no se concibe solo como dato, sino también como operación informativa. Esta nueva era digital trae consigo grandes repercusiones en el plano comunicacional, pero también atraviesa la agencia digital y la participación política de los sujetos. La acumulación y el aceleramiento en los procesos de información -en cantidades y volúmenes indeseados- produce, en ocasiones, desinformación, es decir, abundante información defectuosa que circula por las plataformas digitales. En este ensayo crítico nos preguntamos: ¿Cuáles efectos produce la información defectuosa (o desinformación) sobre la agencia del sujeto en los espacios digitales? Como hipótesis, se sostiene que la información defectuosa motiva una participación defectuosa del sujeto en la operación informativa configurada en el espacio digital. Entendemos que los efectos de participaciones defectuosas sobrelos sujetos en red deben ser considerados un asunto delicadoyuno delos principales foco de estudios actuales. Este ensayo pretende hacerse cargo de esa necesidad.

PALABRASCLAVES: información, informacióndefectuosa, era digital visión de mundo participación defectuosa

\section{ABSTRACT}

Since the late XXth century, society has undergone a digital transformation. Sociallife has been transformed and now operates in a digitalized space, where infor- 
mation is conceived not only as data, but as an informational operation. This new digital era brings with it great repercussions on the communicational level, but it also goes through the digital agency and the political participation of the subjects. The accumulation and acceleration of information processes -in unwanted quantities and volumes- sometimes produces disinformation, that is, abundan faulty information that circulates on digital platforms. This critical study will be guided by the following question: What effect does defective information (or misinformation and disinformation) have over the subject's agency in digital spaces? As an hypothesis, it is argued that defective information motivates a defective participation of the subject in the informational operation, thus constituting a differential operation, understood as one whose energy transformations are born from the interaction between a subject's worldview and defective information, which grants different degrees of falsehood. We understand that the effects of defective participations on network subjects should be considered a delicate

84 matter and one of the main focus of current studies.

KEYWORDS: information, defective information, digital era, worldview, defective participation.

\section{RESUMO}

Desde o final do século XX, a sociedade tem experimentado uma transformação digital. A vida social se transformou e opera num espaço digitalizado onde a informação não é mais concebida apenas como dato, senão também como operação informativa. Essa nova era digital traz consigo grandes repercussões no plano comunicacional, mas também passa pela agência digital e pela participação política dos sujeitos. O acúmulo e a aceleração dos processos de informação -em quantidades e volumes indesejados- produzem, às vezes, desinformação, ou seja, abundante informação defeituosa que circula pelas plataformas digitais. Neste ensaio crítico perguntamo-nos: Que efeito produz a informação defeituosa (ou desinformação) sobre a agência do sujeito nos espaços digitais? Comohipótese, argumenta-seque a informação defeituosa motiva uma participação defeituosa do sujeito na operação informacional configurada no espaço digital. Entendemos que os efeitos das participações defeituosas sobre os sujeitos da rede devem ser considerados um assunto delicado e foco de estudos atuais. Este ensaio visa atender a essa necessidade.

PALAVRAS CHAVES: informação, informação defeituosa, era digital, visão de mundo, participação defeituosa. 


\section{INTRODUCCIÓN}

En las últimas décadas la sociedad ha experimentado una transformación digital que atraviesa y modifica la vida social en su conjunto. Esto genera que la interacción humana tenga lugar o se proyecte en el espacio digitalizado, donde la información ya no es concebida como un mero dato, sino también como una operación informativa. Esta nueva era digital implica novedosos y renovados espacios de interacción entre los sujetos y transformaciones en el campo de la participación política. Asimismo, las denominadas tecnologías de la información y la comunicación (TICs) y las plataformas digitales, aunque cumplen funciones distintas, presentan características y objetivos comunes: ambas posibilitan nuevos espacios sociales y políticos, tienen la facultad de difundir y propagar la información por el espacio digital.

Desde ese punto de vista, la transformación digital ha configurado -y sigue configurando- una sociedad que está mediada por tecnologías digitales, cuyo hito de inicio fue la aparición del Internet, al tiempo que se han evidenciado cambios respecto de la sociedad mediada únicamente por tecnologías y prácticas ligadas a la fotografía analógica, la radio, la televisión y la prensa gráfica en formato papel. Si bien la sociedad actual, inmersa en la era digital, también hace uso de la información como insumo de las nuevas tecnologías, la concepción del proceso de información difiere de lo que sucedía anteriormente, cuando la interacción suponía otros mecanismos de contacto. En la actualidad, los sujetos se encuentran inmersos en procesos de digitalización de la vida social, o, si se quiere, enmarcado por una cultura digital donde los usuarios interactúan de manera cotidiana, ubicua y acelerada con la información circulante. Ahora bien, es necesario caracterizar qué concepto o tipo de información es la que está operando en la sociedad digital y cuál es su rol.

Desde la aparición de la teoría matemática de la información (TMI) y la cibernética, alrededor de la década del 40 del siglo XX, la expansión de las redes de telecomunicaciones ha tenido un aumento exponencial y ha promovido múltiples transformaciones. Con estas dos teorías -más precisamente con la cibernética-se aspiró a pensar y regular los mensajes en el contexto de expansión comunicacional. De ahíquela tesis de Wiener (1958) en Cibernética y sociedad fue que la sociedad debía interpretarse mediante el estudio y el control de los mensajes en el marco de aquello que se comprende como comunicación. El filósofo y matemático norteamericano se proponía estudiar la comunicación entre sujeto y máquina, y -también- entre máquina y sujeto, incluso entre máquina y máquina. En ese sentido, tanto la TMI como la cibernética adelantaron y ayudador a configurar algunos de los principios relacionados con las mutaciones tecnológicas que atraviesa el universo de las tecnologías digitales.

Asimismo, la revolución en las comunicaciones supone cambios en la agencia. Si bien el sujeto tiene una disposición a formar grupos, es decir, cons- 
tituir formas asociativas de vida, los agenciamientos que se promueven en el marco de la sociedad actual alteran el espacio: de un espacio eminentemente físico, material y presencial, se pasa a un espacio digital en donde lo corporal se dispone de otro modo y las interacciones y los mecanismos de encuentro son recreados. Se supone así un nuevo espacio de diálogo: el espacio digital. En tal sentido, la agencia digital se comprenderá como la manera que tienen los sujetos de conectarse y comportarse con el entorno digital, algo que puede llevar a concebir a la agencia como una operación, como se verá más adelante.

De este modo, las transformaciones en la agencia contribuyen a idear y pensar nuevas formas de participación ciudadana y política. Esto implica, en primer lugar, la capacidad reflexiva del sujeto en red de ponderar y evaluar las diversas informaciones que lee y escucha de las distintas plataformas digitales; $y$, en segundo lugar, la facultad de deliberar, llegar a un acuerdo entre sus propias reflexiones y concluir con una decisión. Con su participación el sujeto tiene la posibilidad de formar parte de las acciones ciudadanas, donde critica y reflexiona sobre su situación contingente, contribuyendo a los debates de una comunidad o un colectivo. Sin embargo, esta participación, en algunos casos, puede estar motivada por la circulación de información defectuosa.

En la actualidad, la información cruza el campo de la comunicación, la agencia digital y la participación política de los sujetos en red y se difunde por las diferentes plataformas digitales llegando a distintos usuarios. Sin embargo, y como es obvio, no toda la información que circula en Internet es verídica; de allí la necesidad de preguntarse por las dinámicas complejas de aquello que se convierte en desinformación, es decir, en información defectuosa. La pregunta que guía este trabajo lleva a reflexionar los alcances de la desinformación (o información defectuosa ${ }^{1}$ ) sobre la agencia del sujeto en los espacios digitales. Como hipótesis se sostiene que la información defectuosa motiva una participación defectuosa del sujeto en la operación informativa configurada en el espacio digital.

Para iniciar este recorrido, que liga información defectuosa y participación defectuosa del sujeto -en tanto motivado a una operación informativa diferencial por efectos de la desinformación-, la obra de Simondon, y más específicamente la conceptualización simondoniana de la información, será el punto de partida del artículo, cuyo propósito es abrir algunas reflexiones propias del ensayo teórico que se vale de algunos aportes filosóficos. Por otra parte, la noción de visión de mundo será fundamental para entender cómo el sujeto "acepta" y persiste en el uso o la creencia de la información defectuosa. Así se genera una participación digital que se sostiene con base en dicha desinformación.

El trabajo se ordena en cuatro partes. En primer lugar, se exponen los antecedentes principales del problema, focalizando la atención en cómo se

1 En esta investigación, los términos desinformación e información defectuosa son homólogos. 
produce la transformación digital, la aceleración de las formas de intercambio y los riesgos que provoca en la puesta en circulación de información. En segundo lugar, se despliega la categoría de información defectuosa, para la cual se dará cuenta de una noción de visión del mundo basada en la concepción de Dilthey (2018); luego se caracteriza qué se entiende por espacio digital. En tercer lugar, se conceptualiza la noción de participación defectuosa a partir de la definición simondoniana de información y abordando el doble carácter del concepto -es decir, doble en tanto operación diferencial y sus consecuencias sociales-. Finalmente, se realizan algunas reflexiones sobre los problemas de la participación defectuosa y se formulan algunas posibles líneas de investigación a futuro.

\section{TRANSFORMACIÓN DIGITAL Y VICIOSDE LA INFORMACIÓN}

Un sujeto despierta, y la primera acción que realiza es revisar la entrada de su Smartphone. Ve que le llegaron dos correos, abre una conversación de WhatsApp que no alcanzó a observar el día anterior, revisa sus pasos (0) y agenda una reunión con otras personas por Google Meet. En solo unos minutos, se ejecutaron un gran número de acciones en el espacio digital, cuantificación que solo seguirá incrementándose a lo largo del día. Todas estas acciones son posibles gracias a las herramientas que proporcionan las TICs -su celular, su computador y los programas que usa- y las plataformas digitales, las redes sociales y otros dispositivos que expresan el proceso de digitalización (Echeverría, 2009). Como elemento transversal a todas estas nociones se encuentra la información. Sin embargo, aquel sujeto, que ve su celular por la mañana y, a partir de allí, comienza un día plagado de intervenciones en el espacio digital, no siempre visualiza la magnitud o el alcance que pueden llegar a tener sus acciones, constantes y cotidianas, en el espacio digital. Cada información que el sujeto consume y produce no solo puede alterar la cotidianidad; es decir, cada acción que un sujeto efectúa en línea tiene una gran y real incidencia en su entorno material y está atada a toda una operación informática que excede su mera condición de dato ${ }^{2}$.

La transformación digital reúne muchas y diversas aristas. Los comienzos de Internet datan desde los años de la Segunda Guerra Mundial, cuando en la Escuela Gubernamental de Códigos y Cifrados, con la ayuda de Alan Turing, se tenía como principal motivación descifrar los códigos alemanes de la máquina "Enigma"3

2 Conforme a fines prácticos, y más allá del modo interrelacionado en el que conviven el llamado espacio digital y el llamado espaciofísico o material, en este artículo se establece tal distinción con el propósito de, por unlado, subrayar los cambios producidos en el proceso de digitalización, y, por otra parte, con el fin de singularizar el modo en que tiene lugar la operación informativa en el espacio digital.

3 "Enigma" fue una máquina diseñada para descifrar y cifrar mensajes que los alemanes construyeron, aplicando una idea del ingeniero Arthur Scherbius, cuyo objetivo era codificar las instrucciones de "las tropas de Hittler" (Morales, 2018, p. 52). 
(Morales, 2018). Tiempo después, los estadounidenses, en respuesta al lanzamiento del satélite Sputnik realizado por la Unión Soviética en 1957, crearon una agencia en el Pentágono cuyo objetivo era contribuir al desarrollo tecnológico para elámbito militar al quellamaron Advanced Research Projects Agency $(\mathrm{ARPA})^{4}$, que comenzó a funcionar en 1958 (Morales, 2018).

Otra arista relevante fueron los estudios que Claude Shannon (Shannon \& Weaver, 1949) realizó en Laboratorios Bell, y los ya mencionados trabajos de Norbert Wiener en el campo de la cibernética durante la segunda mitad del siglo XX. Shannon ofreció un modelo de comunicación consistente en reproducir un mensaje de un punto a otro; es decir, una transferencia de un mensaje que se efectúa de acuerdo al viejo esquema de emisor y receptor, en tanto referencias principales de esalínea de transmisión. Por su parte, Wiener le agregó a esta idea la noción defeedback (retroalimentación) a partir dela cual puede pensarse que la información sale del sistema y luego entra, con modificaciones, como efecto de un proceso que involucra al sujeto que responde el mensaje recibido (Filinich \& Chibey, 2020a, 2020b). Estas dos teorías fueron retomadas, años más tarde, por innumerables investigadores del campo de la comunicación, dando lugar a teorizaciones que permitieron reflexionar acerca de la complejidad dela interacción humanay, también, sobrelas singularidades delos nuevos entornos tecnológicos y los recursos puestos en juego por la transformación digital que tiene lugar, de manera acelerada, desde hace más de dos décadas.

En vistas de lo anterior, Morales (2018) menciona que a Tim Berners-Lee se le ocurrió, en los años 90, la innovadora idea de crear un sistema que permitiera enlazar documentos que provenían de computadoras repartidas en Internet resultando "un laberinto de información" (p. 54) que se denominó World Wide Web, o simplemente web, posibilitando el desarrollo de un software específico y motores de búsqueda -siendo Google, en la actualidad, el más conocido y utilizado-, que permiten la inmersión y la exploración de los usuarios. Asimismo, Berners-Lee y su grupo de trabajo crearon el "protocolo HTTP", el "lenguaje HTML" y el "sistema URL", a la vez que desarrollaron el primer navegador (Morales, 2018, p. 54). Todos estos son recursos conocidos y base para la conformación de lo que se considera como la era digital.

Internet puede definirse, siguiendo la propuesta de Nicolas Carr, como una máquina creada para recibir y transmitir información de manera eficiente y automatizada, ha implicado la aspiración de hallar un método algorítmico óptimo que aporte a la "tarea del conocimiento" (Morales, 2018, p. 57). En este sentido, es un espacio virtual en el cual se indexan y almacenan datos, y donde es posible encontrar algoritmos que responden a una cadena de operaciones. En este contexto, la categoría Big Data, en tanto repositorio que se centra en el análisis, el almacenamiento y la acumulación de gran cantidad y volúmenes de datos "producidos por y sobre las personas, cosas o relaciones entre ella"

4 En 1972, la agencia ARPA pasó a llamarse Defense Advanced Research Projects Agency (DARPA). 
(p. 68), juega un papel importante. Al igual que el término Internet de las cosas (IoT), cuya referencia, sirve para referirse al sistema en el cual los artefactos técnicos se conectan a Internet por medio de sensores, lo que permite al artefacto recolectar datos y luego hacer uso de ellos (Hendricks \& Hansen, 2016; Morales, 2018) ${ }^{\mathbf{5}}$.

Por otra parte, otro fenómeno de la era digital corresponde a la realidad virtual. Horrocks (2004) define realidad virtual -según McLuhan- como "la condición 'ontológica y epistemológica' de un 'como sí’” (p. 51). Entonces, esta experiencia del como sí puede verse intensificada por la calidad y la cantidad de la información, lo cual presenta una conexión con los estímulos perceptivos que el usuario vive y experimenta condicionado a su dispositivo digital. En la medida en que el sujeto interacciona con tecnología virtual, puede sentirse parte de su entorno virtual como si fuese parte de su propia realidad (Horrocks, 2004). Así, la interacción entre información (mundo virtual) y respuestas sensomotoras es el principio de una experiencia que puede vivirse de manera tan intensa y real como la realidad misma del usuario.

Hasta aquí se ha hablado de información principalmente como dato. Los algoritmos, el Big Data y la realidad virtual emergen como fenómenos que forman parte de la era digital. Desde este punto de vista, Internet es el hogar de la información digital, la cual no se comprende-en este trabajo- como dato, sino en términos operacionales. Para explicar ese cambio de modalidad es necesario remitir al concepto simondoniano de información.

En su conferencia titulada "La amplificación en los procesos de información”, del año 1962, Gilbert Simondon nos brinda una definición de información. Allí postula que la información es una operación (y no una cosa) que se define por sus transformaciones energéticas y la operación de recepción ( $\mathrm{Si}$ mondon, 2015a).En primer lugar, se refiere alas transformaciones comodisparidades energéticas, que son parte de la operación de constitución y formación del individuo -o ser- en un medio energético metaestable y con potenciales para que continúe con sus transformaciones en el proceso de individuación ${ }^{6}$ (Filinich \& Chibey, 2020a, 2020b). En segundo lugar, la información depende de su efectiva recepción, teniendo en cuenta que en dicho proceso adopta una significación, entendida en un sentido energético y no semántico (Simondon, 2015b; Filinich \& Chibey, 2020a, 2020b).

De allí que cuando la información, comprendida como operación y no como dato, es recibida en grandes cantidades y volúmenes, puede producir re-

5 Por ejemplo, dispositivos conectados a Internet o al Bluetooth que operan yorganizan información sobre el usuario como es el caso de los relojes inteligentes, los cuales tienen la facultad de emparejarse al Smartphone y compartir datos acerca de la persona (horas de sueño, pasos, ritmo cardiaco, entre otros).

6 La individuación, o proceso de individuación, hay que entenderlo como el devenir del individuo. Dicho devenir se desfasa de su entorno, contribuyendo a un sistema, que Simondon sugiere sea metaestable, ya que "el equilibrio estable excluye el devenir"; en cambio, el equilibrio metaestable permite la generación de nuevos potenciales que sirven para "futuras transformaciones" (Simondon, 2015b, p. 11). El concepto de individuación se puede revisar también en Filinich y Chibey, 2020a, 2020b. 
chazo. En ese marco, y merced a las transformaciones digitales antes referidas, es posible identificar algunos vicios que forman parte de los cambios gestados en las últimas décadas e introducir la noción de información defectuosa. Vamos a detenernos ahora en tres vicios o riesgos capaces de ser promovidos por el exceso de información antes referido.

En primer lugar, se puede aludir al término infoxicación, que, como señalan Batista y Valencia (2012), siguiendo la lectura de Brey, implica un exceso de información incapaz de ser absorbida o discriminada; es decir, una intoxicación que sufre el sujeto con relación a su capacidad de discriminar la información recibida. Junto a dicho concepto, es posible integrar y referir a la idea de infodemia. Sánchez y Fernández-Valdés (2020) lo explican como "un gran aumento del volumen de información relacionada con un tema en particular, que puede volverse exponencial en un período corto debido a un incidente concreto como la pandemia actual" (p. 4). Tanto la infoxicación como la infodemia son vicios que afectan al espacio digital y promueven, como se ha observado en coyunturas como la actual, algunos riesgos informativos que derivan en proceso de desinformación. Por su parte, existe un tercer vicio que tiene que ver con el aspecto psíquico del sujeto, saturado de los estímulos que promueve el entorno virtual, al que Byung-Chul Han (2014) entiende como un síndrome ligado al cansancio de la información (Information Fatige Syndrom -más conocido como IFS-, término acuñado por David Lewis en 1996).

En este último caso, la población de usuarios en red, sumergidos en la vorágine tecnológica que permite la recepción permanente de datos, aparecen, desde dicho punto de vista, atravesados por una "creciente parálisis de la capacidad analítica" y la "perturbación de la atención, inquietud general o incapacidad de asumir responsabilidades” (Han, 2014, pp. 64 y 65). De allí que la capacidad analítica se vería entorpecida por el exceso de información, cuyo cansancio psicológico produce, a su vez, una disminución en la capacidad para discriminar la información. Asimismo, si ya es difícil evaluar la pertinencia o rigurosidad de los consumos digitales y rastrear las fuentes de la información que un sujeto recibe a diario, ese estado daría lugar a que la comunicación pueda quedar entrampada en procesos de informaciones defectuosas o desinformación creciente.

Según Hendricks y Hansen (2016), depender, por caso, del vértigo delas redes sociales suele aumentar la difusión y la propagación de creencias falsas, sin que la veracidad del dato, como aspiración, al menos, pueda comprobarse. En esa tormenta de la información, tal como los autores denominan al fenómeno generado por las transformaciones digitales y las nuevas formas de circulación informativa, quedarían enmarcados el llamado cansancio de la información o psicológico, la infoxicación y la infodemia. En otras palabras, siendo el contexto propicio para la generación y la aceptación de información defectuosa, dado que la visualización y la capacidad analítica se debilita por el exceso de 
información ylas habilidades para discriminar información disminuyen frente a los diversos estímulos que aparecen en el espacio digital, a continuación se esboza una serie de precisiones sobre la noción de información defectuosa y lo que su despliegue implica en el espacio digital.

\section{INFORMACIÓN DEFECTUOSA, PROCESO INTERNO, VISIÓN DE MUNDO YESPACIO DIGITAL}

Como se ha referido en los parágrafos anteriores, se pasó de una idea de información como mero dato a una concepción que piensa o define a la información como una operación. Entonces, ¿qué se entiende por información defectuosa o desinformación? En inglés existen dos términos para expresar la idea de desinformación: misinformation y disinformation. El primero alude a la información errónea que no hace daño, es inocua y se difunde de manera accidental, o sin saber conscientemente del error que comunica; el segundo refiere a la misma operación, pero realizada de forma intencional, es decir, que tiene "el fin de mentir deliberada o intencionalmente a otros sobre la verdad” (Estrada-Cuzcano, Alfaro-Mendives \& Saavedra-Vásquez, 2020. p. 97). Es a partir de esa rápida discriminación conceptual que se puede plantear y entender el carácter mediador, desde el punto de vista conceptual, que aquí se le atribuye a la noción de información defectuosa, en tanto incluye el plano accidental y el plano intencional de la información que se difunde; es decir, absorbe los atributos de la misinformation y la disinformation.

Para Floridi (1996), la desinformación es cualquier información que sea creada desde la falta de objetividad, de exhaustividad o de pluralismo. Motivo por la que no podría limitarse a las fake news, sino que incluye también a la propaganda, la damnatio memoriae y la censura ${ }^{7}$. Levi y Guixaró (219) van más lejos al afirmar que la desinformación "no sólo comprende información falsa, sino que también incluye la elaboración de información inventada que se combina con hechos y prácticas que van mucho más allá de cualquier cosa que se parezca a noticias" (p. 15). Como ejemplos, señalan a las "redes de seguidores falsos, videos falseados o manipulados, publicidad dirigida” (y engañosa), rumores y "memes visuales" (Levi \& Guixaró, p. 15).

A partir de las definiciones de Floridi (1996), de Simondon (2015a) y de Leviy Guixaró (2019), aquí se considera información defectuosa a toda aquella operación que interactúa en un proceso interno defectuoso (no solo las fake news) y tiene grados de falsedad y capacidad para transformar al sujeto. Lo cual planteala necesidad dehacer una aclaración: sehabla de información defectuo-

7 Es preciso aclarar que Floridi (1996) se refiere al "process of information" (p. 3) como proceso de creación de la información. En ese sentido, la desinformación se produce en la medida que el proceso de información es "defective" (defectuoso) (Ibid.). Esto no debe confundirse con el concepto de proceso interno que se postula en este artículo, el cual no se refiere a la creación de información, sino a una interacción entre dicha información y la visión de mundo de un sujeto. 
sa, y no de información falsa, porque lo que interesa no es el valor referencial o de verdad de la información, sino su repercusión y efectos sobre los sujetos. En tal sentido, mientras más intensa y abundante sea una información, mayor será el grado de falsedad podría aceptar el sujeto, algo que expone una forma singular-proceso interno-de pensarla interacción entre información ysujeto, y se relaciona con su visión del mundo.

Algo común a todas las formas de información defectuosa es que, al interactuar con un sujeto, contribuyen a formar o consolidar visiones de mundo aparentemente incompatibles con aquellas que están basadas en información que se supone verídica. El funcionamiento de este tipo de proceso interno se explica en los siguientes supuestos:

- para que un sujeto acepte una información defectuosa debe tener como requisito- una visión de mundo particular que sea coherente o esté alineada con ella.

- para seguir aceptándola a lo largo del tiempo, esa visión de mundo debe poder seguir justificándose de alguna forma, es decir, encontrar un sentido que permita el sostenimiento o la creencia en la llamada información defectuosa.

La noción de visión de mundo expuesta es semejante a la idea de concepción de mundo de Wilhelm Dilthey (2018), ya que ambos conceptos incluyen un "sentido" y un "sistema de creencias", aunque la idea de visión de mundo aquí desplegada toma algo de distancia respecto de la propuesta del filósofo alemán.

Vale decir que la concepción de mundo de Dilthey comprende un sistema de creencias afirmativas sobre un evento específico, orientadas con un sentido particular y coherentes con las acciones del sujeto. En otras palabras, es una forma de entender el comportamiento, de acuerdo a la concepción del mundo, que ayuda a aprehender el sentido de un cierto contexto a partir de las acciones de los sujetos que están siendo estudiados. La concepción se funda sobre "una imagen del mundo" (p. 129), así, las acciones de los sujetos, inmersas en situaciones específicas, adquieren sentido en relación con la realidad; la imagen de mundo opera como base "de la estimación de la vida y de la comprensión del mundo" (p. 130).

De manera complementaria, Peñaloza (2015) rescata la concepción de mundo de Dilthey como una "estructura psíquica" que contiene "experiencias vitales" que dan lugar a la comprensión y sentido de la vida y el mundo de un sujeto; en esta línea, la visión de mundo refiere a una totalidad que pretende otorgar sentido y significado a la realidad (p.310). Así, es aquello que se percibe y sirve como fundamento de una explicación, es decir, las creencias que posibilitan las acciones prácticas y teóricas de una comunidad, o de un individuo en particular, y otorgan el sentido a una forma particular de concebir el mundo. 
Dilthey (2018) entiende este sistema de creencias y al sentido en términos semánticos -como también lo hace la Hermenéutica-. Aquí, no obstante, se matiza dicha concepción y se entiende que el sistema de creencias reúne las informaciones y las opiniones de un sujeto, mientras que el sentido es aquello que aporta estructura y dirección - $u$ orientación- a la visión del mundo que tiene el sujeto. De allí que el sistema de creencias permite alojar y alimentar la visión de mundo de un sujeto, mientras que, el sentido sostiene y mantiene dicha concepción en el tiempo: la visión de mundo es entendida como parte de un conjunto de creencias y normas muy arraigadas que dan sentido al mundo de un sujeto particular.

Pero ¿qué ocurre cuándo las creencias en una visión de mundo particular se fundan en eso que se llama una información defectuosa?

Un sujeto se convence de que $p$ es verídica ${ }^{8}$-es decir, logra dar dirección o sentido a $p$-porque, aun teniendo grados de falsedad, es compatible con su sistema de creencias y valores bien organizados (logrando así $p$ un poder de convencimiento mayor incluso que con la información verídica). En esta operación se manifiesta la fuerza dela agencia del sujeto: cuandoéste ha construido una visión de mundo sobre cierto evento a partir de información defectuosa, es plausible que pueda rehusarse a creer en la visión de mundo verídica que se le pueda ofrecer al respecto. E incluso, si se viera enfrentado al desafío de defender su propia visión de mundo como la correcta, es posible que recurra solamente a ella como justificación, fruto de la estructura y dirección antes referida. Así, la brecha que existe entre una visión de mundo defectuosa y una verídica -entendidas, dichas visiones, se recuerda, como repercusión y efectos sobre los sujetos- puede llegar a ser inconmensurable, como la diferencia que existe entre una realidad simulada y una realidad en sí. O, para decirlo de otro modo, la brecha que existe entre realidad en sí y experiencia del como sí: un usuario puede estar experimentando una realidad construida de objetos, cosas, personas, que, si bien son simulaciones muy intensas y vívidas, a la vez, no corresponden a la realidad en sí. Por lo tanto, hay una inconmensurabilidad entre esas dos experiencias, en parte similar a la que hay entre información verídica e información defectuosa.

Hendricks y Hansen (2016) se refieren al espacio proporcionado por el Internet como un marco o entorno de divulgación para la información: "el espacio público en línea es la misiva de la información disponible públicamente para cualquier persona conectada a Internet" (p. 36). Cualquiera puede acceder y producir información en un proceso en el cual "generalmente no hay guardianes de la verdad" (p. 37), y tampoco hay mecanismos o protocolos para rastrear esa verdad propiciando la existencia de información defectuosa, aspecto que se conecta con lo antes comentado sobre la metáfora de la tormenta de informa-

8 Nohayproblemasconceptualesalutilizarel término verídico,pueslos dosmodosdeconcebirla falsedadpresentados al comienzo de la sección no se excluyen entre sí; aquí verídico se entiende como aquello que es creíble por un sujeto. 
ción: no hay mecanismos -suficientemente poderosos- que permitan discriminar entre información verídica e información defectuosa. También parece ser que la información defectuosa tiene más repercusiones en el espacio digital que en el llamado espacio físico, ya que en el primero el sujeto está expuesto a cantidades exorbitantes de información. Aquí aparecen los vicios descritos, infoxicación, infodemia y cansancio psicológico; donde la información, en ocasiones, genera rechazo y, a la vez, aceptación -pues presenta una estética particular que contribuye a ello.

Con relación a lo anterior, Vásquez, Sánchez y Bolívar (2018) señalan que las interacciones de los sujetos en los espacios digitales -redes sociales, páginas de compras, etc.- "hablan" -en cierto modo- de ellos; es decir, los describen, los exponen y, a la vez, los “sobreexponen" (p. 76). En este sentido, una característica del espacio digital consiste en que el contenido toma sentido en función a la interacción con los otros usuarios, en tanto se comparten las percepciones u opiniones y otros pueden visibilizarlo (Vásquez, Sánchez \& Bolívar, 2018). Ese contenido, según el punto de vista de este artículo, no solamente puede ser falso o verídico, sino que genera consecuencias o efectos que contribuyen a la formación de la identidad del sujeto en línea. Por lo tanto, el entorno digital proporciona al sujeto una forma de construir su identidad y de reconocerse frente a otros sujetos mediante su participación, asumiendo - en cierto modoque la información que produce y recibe puede ser defectuosa.

Vásquez, Sánchezy Bolívar (2018) agregan que la subjetividad que surge en los espacios digitales conforma comunidades y colectivos, en tanto el reconocimiento es parte de la construcción de la subjetividad de los usuarios en línea. De esta forma, estos espacios pueden ser vistos como espacios de construcción de ámbitos de cultura y de la subjetividad, ya que en ellos la participación es un elemento crucial. Un sujeto que participa construye creencias y opiniones que sevan alimentando por las respuestas (informaciones) que recibe eintercambia con otros usuarios. En esta dinámica el sujeto adquiere aceptación, credibilidad y confianza en la medida que la información que recibe coincide con la que piensa. No obstante, y como es obvio, la aceptación, la credibilidad y la confianza que pueda proporcionar una información no garantizan su veracidad.

\section{PARTICIPACIÓN CIUDADANA Y PARTICIPACIÓN DEFECTUOSA}

Se ha visto que la participación de un sujeto en un contexto público le permite dar sentido (dirección y orientación) a su visión de mundo. Aquí se puede entender participación, específicamente, como participación ciudadana. Aparici y Osuna (2013) la definen de este modo: "Formar parte, colaborar con los demás y conformar el grupo de consenso para conseguir metas comunes. ( ) Un derecho de la ciudadanía, y así debe ejercerse de forma libre, crítica y responsable en todos los sectores de la vida" (p. 138). 
En esa línea, la participación es un derecho ciudadano que responde a la libre agencia de un sujeto que ejecuta una acción-individual o colectivamenteen un entorno público, donde la regulación introduce una tensión entre libre agencia y normatividad. Asimismo, la participación ciudadana tiene repercusiones en la comunicación y la política, siendo el entorno digital un espacio que en la actualidad atraviesa las estrategias, la discusión y la puesta en circulación de información.

La transformación digital ha producido cambios profundos en el campo político a nivel global, ya que el avance tecnológico permite que los sujetos pueden acceder a información variada de un modo permanente, además de que pueden ser partícipes de su gestión y producción, alterando en partelos modos de hacer política: lo referido a la publicidad, la digitalización de las campañas, las formas de financiamiento (Vercelli, 2013, p. 116). Es en ese contexto que Vercelli (2013) hace mención a los gobiernos abiertos; un tipo de gobierno que utiliza a las TICs y a las plataformas digitales para promover la transparencia en las gestiones políticas, la participación ciudadana, la colaboración entre instituciones políticas (entre gobiernos, ciudadanos, organizaciones, sindicatos) y la administración de los bienes intelectuales. Y, en ese marco, la información digital constituye uno de sus recursos principales. Asimismo, Vercelli (2013) introduce una cuestión fundamental: si se puede hablar de gobiernos abiertos, ¿es posible hablar de "nuevas formas de participación política" o "ciudadanías abiertas" en la era digital? p. 118).

Desde esta perspectiva, y fijando la atención en el espacio en red y las interacciones múltiples promovidas por la digitalización, también es posible hablar de participación defectuosa. Es decir, una participación ciudadana en el espacio digital basada en una operación diferencial que supone futuras transformaciones -mediante la transducción, o reacción en cadena-. Por tanto, es preciso subrayar el doble carácter de este concepto: por un lado, la operación diferencial tiene efectos sobre el sujeto -en tanto se configura una identidad online sostenida en el modo de presentación y carácter de la participación-, mientras que, por el otro, la amplificación transductiva del flujo informacional puede traer consecuencias que van más allá del sujeto.

Al respecto, vale hacer tres consideraciones. En primer lugar, aquí se acota la participación defectuosa al espacio digital, aunque -como ya se adelantó-el concepto no está necesariamente restringido a dicha espacialidad, sino que también puede funcionar u operar en el espacio físico-presencial -tal la esquematización propuesta al inicio del artículo-. En segundo lugar, la participación defectuosa incluye tanto al ámbito accidental como intencional de la divulgación de información. En tercer lugar, la conceptualización propuesta por Simondon ofrece insumos teóricos -como las nociones de información, de transducción y de transindividualidad-para avanzar en su comprensión. Sin pretender total exhaustividad, a lo mencionado sobre información se le 
suma ahora, a partir de los planteos e interpretaciones realizados por Filinich yChibey (2020a, 2020b) y D’Andrea y Campoamor (2020), algunas precisiones sobre el uso que Simondon hace de esos conceptos.

Vale recordar que Simondon (2015a) define la información como una operación donde ocurren transformaciones energéticas que, al ser recibidas, se cargan de significación. Tomando en consideración el léxico simondoniano, se considerará aquí como operación diferencial a las operaciones que ocurren en una participación defectuosa; es decir, aquella cuyas transformaciones energéticas nacen de la interacción entre la visión de mundo de un sujeto y una información defectuosa. Estas operaciones tomarán diferentes grados de falsedad (a lo que se puedellamar diferente intensidad de falsedad) y dan fuerza a la visión de mundo.

Ahora bien, para comprender los efectos de la información defectuosa sobre el sujeto (y, con ello, más allá del sujeto) es necesario -y podría ser útil para futuras investigaciones- un abordaje sostenido en cuatro conceptos: la amplificación transductiva, la transindividualidad, el modo de entender la falsedad por intensidad y las relaciones performativas.

En primer lugar, Simondon (2015b) define como amplificación transductiva a "una operación física, biológica, mental, social, por la cual una actividad se propaga progresivamente en el interior de un dominio" (p. 21). Simondon ofrece como ejemplo la expansión de un cristal; una operación que comienza en un germen y se expande en todas direcciones (Simondon, 2015b). En tal sentido, la amplificación transductiva es opuesta a la regulación y control de la información propuestas por la TMI yla cibernética (Filinich \& Chibey, 2020b). Según la descripción de Simondón, es posible afirmar que la participación defectuosa también se amplifica transductivamente: se difunde, y expande la información defectuosa por la red de manera indefinida (transformación energética tras transformación).

En segundo lugar, se encuentra el concepto de transindividualidad, la cual supone que, en la operación informativa, el individuo va más allá de sí mismo en su interacción con el medio asociado, y esto da lugar al espacio delo colectivo (D’Andrea \& Campoamor, 2020). A medida que la información defectuosa se extiende transductivamente por el dominio de un sistema, se intensifican su falsedad y se expande más allá del sujeto o al ámbito de lo transindividual. Efectivamente, a mayor intensidad de falsedad de la información, mayor es el impacto concreto de los efectos: produce posibilidades de visión de mundo cada vez más distorsionadas y alejadas de la información verídica.

Es pertinente, por tanto, señalar la existencia de dos modos de entender la falsedad: 1) Modo referencialy 2) Modoporintensidad. El primero entiende a la falsedad por oposición a la verdad -según su criterio de verdad, la información solo puede ser verdadera o falsa-. Mientras que el modo por intensidad no hace una declaración binaria sobre la falsedad o verdad absoluta de una informa- 
ción, sino que admite grados de falsedad. Esto se relaciona con la intensidad de la experiencia de un sujeto: mientras más convencido el sujeto está acerca de la plausibilidad de una información defectuosa, más intensos son sus grados de falsedad y, por tanto, más intensa es la participación defectuosa y sus efectos sobre el sujeto y lo colectivo, en tanto se acelera o expande su circulación.

El cuarto concepto referido, las relaciones performativas, sirve como complemento para pensar el modo por intensidad de entender la falsedad. En esa línea, Trevor Paglen (2019) plantea un tipo de imagen digital que "está siendo producida por máquinas y para máquinas", en un proceso del cual el ser humano no forma parte necesariamente (p. 1). Dado que este tipo de imagen es distinta a las circulantes en la cultura visual previa a la era digital (por ejemplo, la fotografía analógica), el autor sostiene que las imágenes digitales -en generalse deben entender como parte de un territorio de operaciones y ejecuciones, y no de representaciones; y propone analizar las imágenes digitales desde sus relaciones performativas, dejando atrás la concepción representacional (Paglen, 2019). Esto implica analizar las imágenes digitales a partir de sus ejecuciones, es decir, del modo en que interactúan con el mundo y/o con máquinas. Esta definición de imagen digital permite dialogar sobre sus efectos pragmáticos sobre la cultura y, por lo tanto, se considera que la información defectuosa, al igual que las imágenes digitales, operan bajo esta lógica de relaciones performativas y colectivas.

En esta línea, Celis (2019) afirma que "es necesario pensar la imagen en tanto información" (p. 91) desde una perspectiva pragmática (como zona operacional) y no desde una perspectiva semántica (o atenta a lo que significa). De esa manera, la imagen puede ser entendida, al igual que la información, como una zona o territorio donde se efectúan constantes transformaciones energéticas. Esta conexión entre imagen e información rescata la interpretación simondoniana de la información: pone el foco en su sentido energético.

La operación diferencial se produce justamente en esta zona operacional donde la información defectuosa, si el sujeto permite cierto grado de falsedad, se adhiere al sistema de creencias, es decir, a la visión de mundo y se amplifica (sobrevive) encontrando sentido. Los efectos de la participación defectuosa, entonces, se miden según su intensidad performativa: su intensidad de interacción con la colectividad más allá del sujeto. De esta manera, el modo referencial de entender la falsedad sería reemplazado mayormente por este modo de entender la falsedad por intensidad.

Las relaciones performativas desplegadas en esta zona operacional producen efectos en la agencia digital del sujeto, pues una participación defectuosa despliega la potencialidad de continuar en la misma línea en otra participación del mismo calibre. Específicamente, una participación defectuosa tiene la potencialidad de expandirse e intensificarse en el medio 
digital, afectando no solo al sujeto sino a la colectividad, en tanto involucra sus relaciones con otras informaciones, cosas y usuarios (Simondon, 2015b; Filinich \& Chibey, 2020b).

Un ejemplo concreto podría ser el siguiente: un político con autoridad y legitimidad social realiza una participación defectuosa mediante la plataforma de Google Meet: comparte una fake news sobre la prevención del COVID-19 que recibió de parte del primer ministro, quien, a su vez, la obtuvo desde una fuente dudosa. La información es creíble para el político porque se adecua a su sistema de creencias, porque encuentra sentido y porque supone una visión de mundo que tanto el político como el primer ministro comparten. Los ciudadanos también podrían encontrar creíble aquella información, más aún por la autoridad de quien la difunde y por el contexto particular en la que se enuncia. Esta participación compromete así a otros sujetos, que se ven afectados y expanden la información defectuosa por efecto de la amplificación transductiva; y en este caso, además, se muestra una operación diferencial que expone la intensidad con la cual el político cree en la información defectuosa y la visión del mundo de los usuarios.

Asimismo, tanto la infoxicación como la infodemia y el cansancio psicológico pueden incidir y ser agravantes de esta participación defectuosa, e intensificar los grados de falsedad de la visión de mundo -tanto del político, como de su portavoz y el o los sujetos que reciben la información-. En otras palabras, como la difusión de esta participación no es controlada, tiene efectos performativos.

\section{CONSIDERACIONES FINALES}

En la primera parte del artículo se ofreció un panorama general de los conceptos de TICs, plataformas digitales e información, definiendo a esta última como una operación energética, lo cual supone ir más allá que la idea de dato. Luego se describieron los principales acontecimientos históricos de la transformación digital, a la vez que se desplegaron los potenciales vicios que pueden generar los actuales procesos de puesta en circulación y producción informativa. La posterior definición del concepto de desinformación defectuosa, el rol que juega la visión de mundo del sujeto y la precisión dada a la idea de espacio digital permitió, en tal sentido, exponer los alcances de este escrito: describir las principales características del proceso interno, la dinámica entre información defectuosa y la visión del mundo del sujeto. Para tal fin, en la parte final, se esbozaron, brevemente, los alcances pragmáticos y la incidencia-en lo colectivo- de la llamada participación defectuosa.

Sobre la base del doble carácter del concepto de participación defectuosa, es decir, la operación diferencial donde incide la información defectuosa y sus consecuencias transindividuales, se dejaron planteados algunos interrogantes 
acerca de sus efectos, lo cual conlleva consecuencias performativas -ligadas a la identidad que proyecta el sujeto y su visión del mundo- y colectivas -en tanto operación que se realiza en red-. En ese marco, fue observado que la participación se sitúa en un contexto de tormenta de la información que genera condiciones para el despliegue de vicios o riesgos comunicativos, clasificados como infoxicación, infodemia y cansancio psicológico.

En términos generales, son dos los problemas que conlleva la participación defectuosa en relación con su entorno digital. En primer lugar, la participación defectuosa supone un alto grado de inmersión y convencimiento con respecto a la información defectuosa que está a la base de esa participación, más aún si ésta se multiplica por la red. Aquílos grados de falsedad juegan un rol relevante, ya que estos grados intensifican y amplifican la experiencia de los sujetos. Para un sujeto, su visión de mundo produce convencimiento e inmersión por los grados de falsedad que contiene dicha información, sobre todo si se recibe la información en grandes volúmenes; pues a mayor volumen de información, más se intensifican los grados de falsedad. Las consecuencias de la participación defectuosa llegan a más usuarios, ya que se expanden transductivamente por la red, más allá del sujeto. La información se multiplica y vocifera en las plataformas digitales y llega a una cantidad inédita de nuevos usuarios.

Lo anterior lleva al segundo problema de este tipo de participación, conectado con los sesgos que el sujeto puede experimentar. Si una autoridad política (confiable y legítima para los ciudadanos) efectuara una participación defectuosa, es plausible que muchos ciudadanos puedan disminuir sus dudas, acatar lo establecido y, ocasionalmente, expandir el mensaje. Ahora bien, los sujetos que pertenecen a una colectividad digital tenderán a afirmar y confirmar sus propias creencias y opiniones con su colectividad o grupo de pertenencia, algo que no es, por supuesto, patrimonio de la participación en entornos digitales. Estefenómeno responde a sesgos, visiones o creencias, que atañen tanto a quien realiza una participación y a quien la presencia. En ambos casos, sea proveniente de una "autoridad política", o sea parte de un colectivo digital, la dinámica que adquiere la participación defectuosa transciende al sujeto que la efectúo y se expande por la red. Esto genera consecuencias en cadena ligadas al proceso de circulación digital, a la aceleración de los intercambios e interacciones y a la intensidad de los grados de falsedad.

En suma, los efectos de las participaciones que los sujetos realizan en el espacio digital son considerados aquí como un asunto delicado que merece la reflexión filosófica, en general, y el aporte de la Filosofía de la Tecnología, debido a que el vínculo que se teje en torno de las tecnologías da marco para la acción y la configuración de subjetividades en el mundo actual.

El carácter ensayístico de este artículo pretendió, en tal sentido, abrir una posible línea de indagación sobre la participación ciudadana en el entorno digital, espacio que aparece fuertemente tensionado por la amplificación y la di- 
fusión de eso que sellama información defectuosa. De allílas puntualizaciones realizadas sobre el modo de entender la información yla posibilidad de trabajar con base en enfoques teóricos que, más allá de la falsedad no representacional, piensa en la falsedad por intensidad. Teniendo en cuenta que en la era digital se produce desinformación en grandes cantidades y volúmenes, se considera que la conceptualización de participación defectuosa pretende ser una propuesta que aporte para su análisis.

En ese marco es que pueden delinearse futuras líneas de investigación, una en el ámbito de la tecnología, y otra acerca de la dimensión política del fenómeno. En primer lugar, el Internet de las cosas (IoT), un tópico de gran actualidad, supone abrir la reflexión a la hora de pensar el vínculo del sujeto con los artefactos tecnológicos. ¿Cuáles efectos concretos podrían producirse si el sujeto que promueve una participación defectuosa está conectado simultáneamente a distintos artefactos tecnológicos? ¿Aumentaría la intensidad de esa información?

En segundo lugar, con relación a los llamados gobiernos abiertos, vale remarcar que han generado nuevas formas de participación ciudadana ligadas al espacio digital. Esto trae beneficios -algunos de ellos señalados en el artículo-, pero también puede generar vicios en la trasmisión de información. En tal sentido, y para finalizar, se pueden dejar planteados algunos interrogantes: ¿Cuál es el rol de la deliberación en la acción y participación política en el espacio digital? ¿Los gobiernos abiertos deberían formar y educar sobre la participación ciudadana en red? Temas que pueden dar lugar a distintas investigaciones y desafíos abiertos por la transformación digital.

\section{REFERENCIAS}

Aparici, R. \& Osuna, S. (2013). La cultura de la participación. Revista Mediterránea de Comunicación, 4(2), 137-148. DOI: 10.14198/MEDCOM2013.4.2.07

Batista, R. J. \& Valencia, H. B. (2012). La fragmentación como universalidad: el miedo a la hiperinformación en la sociedad del conocimiento. Encuentros, 10(2), 129-138.

Celis, C. (2019). Notas sobre el estatuto político de la imagen en la era de la visión artificial. Revista Barda, 8(5), 89-106.

D’Andrea, A. \& Campoamor, E. (2020). La computación en el marco de un nuevo proyecto humanista: Releyendo a Dijkstra y Simondon. Pensando. Revista de Filosofía, 23(11), 106-118.

Dilthey, W. (2018). Teoría de la concepción del mundo. Ciudad de México: Fondo de Cultura Económica.

Echeverría, J. (2009). Cultura digital y memoria en red. Arbor, 737(185), 559-567. 
Estrada-Cuzcano, A., Alfaro-Mendives, K. \& Saavedra-Vásquez, V. (2020). Disinformation y Misinformation, Posverdad y Fake News: precisiones conceptuales, diferencias, similitudes y yuxtaposiciones. Información, cultura y sociedad, (42), 93-106. DOI: https://doi.org/10.34096/ics.i42.7427

Filinich, R. \& Chibey, T. (2020a). Becoming and Individuation on theEncounter between Technical Apparatus and Natural System. M/C Journal, 23(4). DOI: https://doi. org/10.5204/mcj.1651

Filinich, R. \& Chibey, T. (2020b). QATIPANA: Processes of Individuation on the Relationship Between Art, Machine and Natural Systems. Critical Hermeneutics, 4(1), 65-88. DOI: https://doi.org/10.13125/CH/4320

Floridi,L.(1996). Brave.Net. World:TheInternet as a disinformation superhighway? The Electronic Library, 14(6), 509-514. DOI: http://dx.doi.org/10.2139/ssrn.3128817

Han, B.-C. (2014). En el enjambre. Barcelona: Herder Editorial.

Hendricks, V.F. \& Hansen,P.G. (2016). Infostorms. Whydo we'like'? Explainingindividual behavior on the social net. Berne: Springer.

Horrocks, C. (2004). Marshall McLuhan y la realidad virtual. Barcelona: Gedisa.

Levi, S. \& Guixaró, R. (2019). Fake news y desinformación. Barcelona: Rayo Verde.

Morales, U. R. (2018). El ciudadano digital: Fake news y posverdad en la era de Internet. Ciudad de México: Océano.

Paglen, T. (2019). Imágenes invisibles, laFuga, 22. Recuperado de: https://lafuga.cl/ imagenes-invisibles/944

Peñaloza, G. (2015). Una mirada desdela Didáctica de las Ciencias al concepto de visión del mundo. Educación y humanismo, 17(29), 308-320.

Sánchez, A. \& Fernández-Valdés, M. (2020). Comportamiento informacional, infodemia y desinformación durante la pandemia de COVID-19. Anales de la Academia de Ciencias de Cuba, 10(2). Recuperado de: http://www.revistaccuba. sld.cu/index.php/revacc/article/view/882

Shannon, C. \& Weaver, W. (1949). The mathematical theory of communication. Chicago: University of Illinois.

Simondon, G. (2015a). Comunicación e información. Buenos Aires: Editorial Cactus.

Simondon, G. (2015b).Laindividuación alaluzdelasnociones deformaydeinformación. Buenos Aires: Editorial Cactus.

Vásquez, A., Sánchez, L. \& Bolívar, W. (2018). Los espacios digitales en permanente definición y construcción. Un análisis desde los elementos formativos. Pedagogía $y$ Saberes, 48, 71-82. 
Vercelli, A(2013).La participación ciudadana en la era digital. Análisis delastecnologías digitales que se utilizan para la gestión de derechos ciudadanos. Virtualis. Revista decultura digital, 4(7), 115-129. Recuperado de: https://www.revistavirtualis.mx/ index.php/virtualis/article/view/72/59.

Wiener, N. (1958). Cibernética y sociedad. Buenos Aires: Sudamericana.

* Contribución: el trabajo fue realizado íntegramente por la autora.

* Nota: el Comité Editorial de la revista aprobó la publicación del artículo.

\section{(cc) BY}

Artículo publicado en acceso abierto bajo la Licencia Creative Commons - Attribution 4.0 International (CC BY 4.0).

\section{IDENTIFICACIÓN DE LAAUTORA}

Tamara Jesús Chibey Rivas. Licenciada en Filosofía, Universidad Alberto Hurtado(Chile). Miembro tesista, Centro de Estudios Mediales, Universidad Alberto Hurtado (Chile). Coordinadora, junto a Roberto Rubio, Grupo de Estudio “Información, Mediosy Cultura”, Centro de Estudios Mediales, Universidad Alberto Hurtado (Chile). Sus áreas de interés son: filosofía de la tecnología, filosofía de la información, estudios mediales, cultura digital, filosofía dela psicologíay problema dela irracionalidad. 